\title{
Electrochemical Cycling and Lithium Insertion in Nanostructured $\mathrm{FeF}_{3}$ Cathodes
}

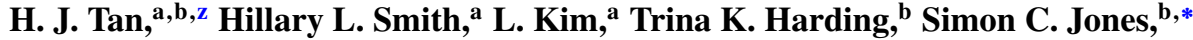 \\ and B. Fultz ${ }^{\text {a,* }}$
}

${ }^{a}$ Keck Laboratory, California Institute of Technology, Pasadena, California 91125, USA

${ }^{b}$ Contour Energy Systems, Azusa, California 91702, USA

\begin{abstract}
The cycle lives for cathodes of nanocrystalline iron trifluoride $\left(\mathrm{FeF}_{3}\right)$ were measured in rechargeable lithium batteries at different depths of discharge. When the discharge was limited to less than one $\mathrm{Li}^{+}$ion per $\mathrm{FeF}_{3}$, both the cycle life and energy efficiency were considerably greater than when converting $\mathrm{FeF}_{3}$ into $\mathrm{Fe}$ and $\mathrm{LiF}$ in deep discharge. An in situ X-ray diffractometry (XRD) study of the $\mathrm{FeF}_{3}$ cathode during its initial discharge to $\mathrm{LiFeF}_{3}$ showed a continuous change of the $\mathrm{FeF}_{3}$ diffraction pattern, indicating $\mathrm{Li}^{+}$ insertion into the rhombohedral $\mathrm{FeF}_{3}$ causing distortion of its lattice parameters. Electrochemical cycling is most reversible when this mechanism occurs in the absence of other changes in the crystal structure.

(C) 2014 The Electrochemical Society. [DOI: 10.1149/2.096403jes] All rights reserved.
\end{abstract}

Manuscript submitted September 23, 2013; revised manuscript received December 30, 2013. Published January 16, 2014.

The secondary lithium battery is the electrochemical energy storage technology of highest performance today, as yet unmatched in energy density and robustness in charge-discharge cycling. ${ }^{1,2}$ The high energy density is directly attributable to the large voltage difference between the electrode materials and their substantial capacity for reversible lithium storage, although the fundamental reasons for their good cycling performance are less well understood. Metal fluorides, including $\mathrm{FeF}_{3}, \mathrm{CoF}_{3}, \mathrm{NiF}_{2}$, and $\mathrm{CuF}_{2}$, have attracted recent attention as cathode materials. ${ }^{3}$ Iron trifluoride, $\mathrm{FeF}_{3}$, stands out as a potential electroactive material because of its low cost, relatively low molecular weight, and high reduction potential (owing to the highly ionic Fe-F bond) leading to high theoretical capacity and specific energy/energy density.

Early studies on pristine $\mathrm{FeF}_{3}$ as a cathode against lithium metal demonstrated an initial discharge capacity of $140 \mathrm{mAh} / \mathrm{g}$ that decreased to $80 \mathrm{mAh} / \mathrm{g}$ upon cycling. ${ }^{4}$ The low electrical conductivity and resulting poor rate capability of $\mathrm{FeF}_{3}$ has been improved by reducing its crystal size and preparing carbon- $\mathrm{FeF}_{3}$ nanocomposites. Carbon coating and particle-size reduction led to reports of high capacity from $300 \mathrm{mAh} / \mathrm{g}$ to $1000 \mathrm{mAh} / \mathrm{g}$ depending on the procedure employed. ${ }^{5-10}$ These increased capacities have been associated with electrochemical formation of $\mathrm{Fe}$ and $\mathrm{LiF}$. This reaction was investigated by solid state nuclear magnetic resonance (SS-NMR) and X-ray diffractometry (XRD). ${ }^{11}$ The reverse reaction to recover $\mathrm{FeF}_{3}$ from $\mathrm{Fe}$ and $\mathrm{LiF}$ was not observed by XRD, and many details from NMR remained ambiguous owing to the large amount of $\mathrm{Li}$ in the electrolyte residue or SEI. On the other hand, cathode materials prepared from nanocomposites of $\mathrm{LiF}$ and $\mathrm{Fe}$ in a discharged state showed a capability of cycling up to 200 cycles. $^{13}$ The cathode in a discharged state can be alternatively prepared by reducing $\mathrm{FeF}_{3}$ with $\mathrm{Li}_{3} \mathrm{~N},{ }^{14}$ or with $\mathrm{LiF}$ to form $\mathrm{Li}_{x} \mathrm{FeF}_{3} .{ }^{15}$

Many of these studies on nanostructured materials reported impressive capacities, much higher than the commercialized cathode materials such as $\mathrm{LiCoO}_{2}, \mathrm{LiMn}_{2} \mathrm{O}_{4}, \mathrm{Li}\left[\mathrm{NiMnCo}_{2} \mathrm{O}_{2}\right.$, and $\mathrm{Li}[\mathrm{NiCoAl}] \mathrm{O}_{2}$ which have a capacity ranging from $100 \mathrm{mAh} / \mathrm{g}$ to $170 \mathrm{mAh} / \mathrm{g}$. However, the work to date indicates that the majority of the extended capacity for $\mathrm{FeF}_{3}$ is realized at lower potentials than for oxide cathodes, requiring a lower practical cutoff voltage of $1 \mathrm{~V}$ and displaying a large hysteresis of approximately $1 \mathrm{~V}$ between charge and discharge cycles. ${ }^{16,17}$ In addition, the performance of this material over a large number of cycles remains unclear.

It is generally agreed that the lithiation of $\mathrm{FeF}_{3}$ occurs in two stages, as first proposed by Badway et al. ${ }^{5,6}$ Stage 1 is the reduction of $\mathrm{Fe}^{3+}$ to $\mathrm{Fe}^{2+}$, with a theoretical reduction potential of $3.44 \mathrm{~V}$ versus $\mathrm{Li}^{+} / \mathrm{Li}$ and an attractive theoretical capacity of $237 \mathrm{mAh} / \mathrm{g}$, storing one charge per $\mathrm{FeF}_{3}$. The cutoff voltage for Stage 1 is approximately

*Electrochemical Society Active Member.

${ }^{\mathrm{z} E-m a i l: ~ h j t a n @ c a l t e c h . e d u}$
2 V. Stage 2 converts the stoichiometric $\mathrm{LiFeF}_{3}$ into $\mathrm{Fe}$ and $\mathrm{LiF}$, with an additional capacity of $475 \mathrm{mAh} / \mathrm{g}$. There have been many investigations of the reaction dynamics of these two stages, but the transition between the two stages remains unclear. A computational study using density functional theory reported that the original $\mathrm{ReO}_{3}$ structure of $\mathrm{FeF}_{3}$ changes to $\mathrm{Li}_{x} \mathrm{FeF}_{3}(0<x<1)$ with an unstable rutile structure before further decomposing to $\mathrm{LiF}$ and $\mathrm{Fe} .{ }^{17}$ However, a new crystal structure of $\mathrm{LiFeF}_{3}$ was believed to form after one $\mathrm{Li}$ intercalation, but some of the remaining $\mathrm{FeF}_{3}$ diffraction peaks were also observed and could not be explained as part of the new phase. ${ }^{12}$ Furthermore, an investigation using XRD and Mössbauer conducted during electrochemical cycling of chemically synthesized $\mathrm{Li}_{0.5} \mathrm{FeF}_{3}$ in the $\mathrm{FeF}_{2}$ rutile structure demonstrated both reversibility and structural stability. ${ }^{15,18}$ Another study proposed two-phase intercalation with lithium ions first filling the (204) plane in the $\mathrm{FeF}_{3}$ rhombohedral unit cell to form $\mathrm{Li}_{0.5} \mathrm{FeF}_{3}$, followed by further lithiation to form $\mathrm{LiFeF}_{3}{ }^{11}$ Today, although a chemical reduction has been demonstrated, ${ }^{14,15,18}$ there is scant experimental evidence to support the electrochemical formation of a rutile structure from the rhombohedral $\mathrm{FeF}_{3}$. It also remains unclear if the reduction of $\mathrm{Fe}^{3+}$ to $\mathrm{Fe}^{2+}$ occurs within a single crystal structure, or if new phases nucleate during the reaction.

These questions about the two stages of lithiation extend to questions about electrochemical performance. First, what is the effect of discharge depth on reversibility and cycle life? Second, how does $\mathrm{FeF}_{3}$ accommodate the insertion of lithium into its crystal structure? We addressed the first question by evaluating cycle life and capacity fade for different discharge voltage cutoffs. Cycling between $\mathrm{FeF}_{3}$ and $\mathrm{LiFeF}_{3}$ (Stage 1) was compared to cycling with deep discharges to $\mathrm{LiF}$ and $\mathrm{Fe}$ (Stages 1 and 2), and we report very large and systematic changes in cycle life with changes in the cutoff voltage for discharge. To address the second question, we performed an in situ XRD study on the structural changes during the first discharge of nanostructured $\mathrm{FeF}_{3}$, and we offer a simple mechanism for lithiation between the compositions $\mathrm{FeF}_{3}$ and $\mathrm{LiFeF}_{3}$.

\section{Experimental}

The active cathode material was prepared by sealing equal masses of pristine $\mathrm{FeF}_{3}$ (Alfa Aesar, 99.9\%) and super P carbon black (Timcal) in a steel vial in a high-purity argon atmosphere. Ball-milling was performed with a Fritsch Planetary Mono Mill for 36 hours at $200 \mathrm{rpm}$ using a steel ball-to-powder weight ratio of 42:1. A mixture of $85 \mathrm{wt} \%$ ball-milled material and $15 \mathrm{wt} \%$ polytetrafluoroethylene (PTFE) powder in isopropanol was rolled into a freestanding film $50 \mu \mathrm{m}$ in thickness. After the solvent was evaporated, the film was punched into $16 \mathrm{~mm}$-diameter circles with a load of $2 \sim 2.2 \mathrm{mg} / \mathrm{cm}^{2}$, and sealed in 2016 coin-cell cans with lithium metal as the counter electrode and an electrolyte solution of $1 \mathrm{M} \mathrm{LiPF}_{6}$ in 1:1 or 3:7 ethylene carbonate (EC) and dimethyl carbonate (DMC). The same anode 
and electrolyte solution were used for pouch cell preparation, where the cathode material was pressed onto an aluminum mesh $30 \mathrm{~mm}$ $\times 30 \mathrm{~mm}$ and $200 \mu \mathrm{m}$ in thickness $\left(\sim 5.7 \mathrm{mg} / \mathrm{cm}^{2}\right)$. The mesh was sealed into a pouch with a $20 \mathrm{~mm} \times 20 \mathrm{~mm}$ polyethylene window at the center of one side. Coin cells were cycled at a constant current of $\pm 142 \mathrm{~mA} / \mathrm{g}(\sim \mathrm{C} / 5)$ using an Arbin cell cycler. The pouch cell was cycled in situ with a rate of $2.37 \mathrm{~mA} / \mathrm{g}(\sim \mathrm{C} / 100)$ using a Versastat potentiostat.

$\mathrm{X}$-ray diffraction (XRD) patterns were measured using $\mathrm{Cu} \mathrm{K} \alpha$ radiation. In situ XRD measurements were performed with the pouch cell oriented for reflection. Rietveld analysis was used to determine lattice parameters and crystal size. CrystalMaker ${ }^{\circledR}$ and CrystalDiffract ${ }^{\circledR}$ software packages were used to design unit cells and simulate XRD patterns. A Tecnai TF30 field-emission transmission electron microscope (TEM) was used for imaging the cathode active material nanocomposite at $300 \mathrm{kV}$ bias. The sample was dispersed in ethanol and prepared on a C-Flat ${ }^{T M}$ holey carbon grid. Bright-field and darkfield images were acquired using a $10 \mu \mathrm{m}$ objective aperture. The electron diffraction patterns were acquired using a $10 \mu \mathrm{m}$ selectedarea diffraction (SAD) aperture.

\section{Results}

Materials characterization.- The XRD patterns of the pristine $\mathrm{FeF}_{3}$ and the ball-milled carbon- $\mathrm{FeF}_{3}$ nanocomposite are shown in Fig. 1. Ball-milling results in significantly broader peaks, indicating a crystallite particle size of $18 \mathrm{~nm}$ by Rietveld analysis and Scherrer equation. An additional peak, the (002) peak of graphite, is visible in the cathode material in Fig. 1(b). These results are consistent with previous studies of $\mathrm{FeF}_{3}$ with similar material preparation. ${ }^{5,6,11} \mathrm{FeF}_{3}$ is commonly indexed to a $\mathrm{R} \overline{3} \mathrm{c}$ rhombohedral crystal structure. ${ }^{5,6,11}$ However, the unit cell is only slightly distorted from the cubic $\mathrm{ReO}_{3}$ structure, having a decrease in $\alpha$-angle from $90^{\circ}$ to $88.23^{\circ}$. This shearing of the unit cell causes the diffraction observed at $33^{\circ}, 40^{\circ}$, and $54^{\circ} 2 \theta$ to split into two peaks. When particle sizes are small, however, there is considerable peak overlap, so for simplicity we use the $\mathrm{ReO}_{3}$

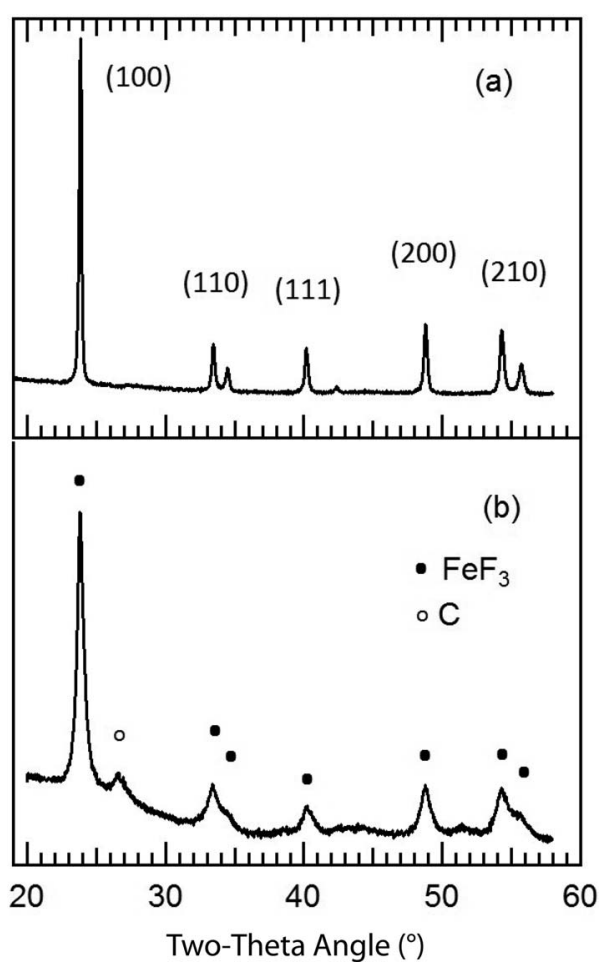

Figure 1. (a) XRD patterns from $\mathrm{FeF}_{3}$ as obtained, and (b) the cathode material comprising carbon- $\mathrm{FeF}_{3}$ prepared by ball-milling.
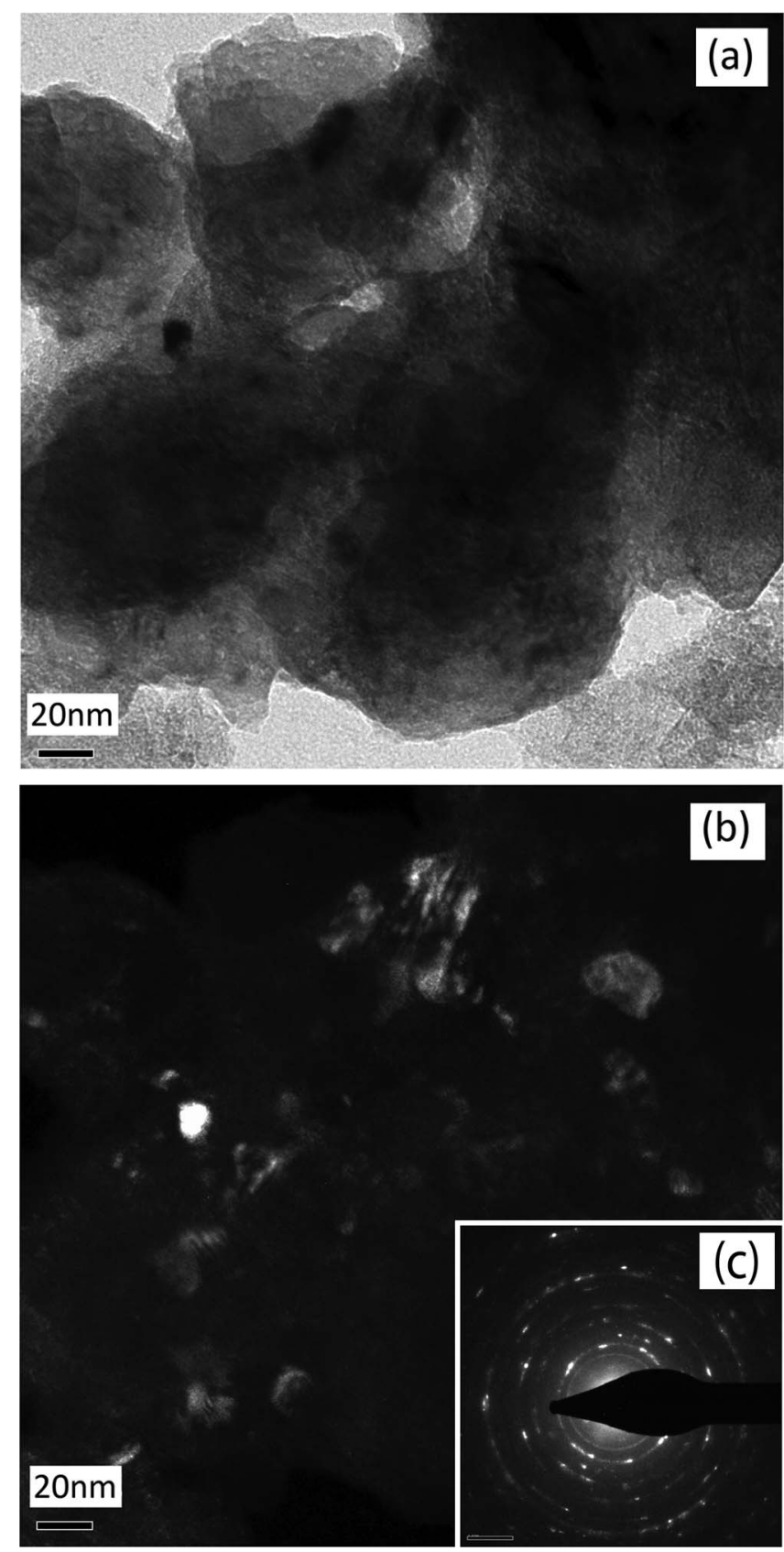

Figure 2. Images of the ball-milled carbon- $\mathrm{FeF}_{3}$ composite: (a) bright-field TEM image, (b) dark-field TEM image taken from the $\mathrm{FeF}_{3}$ (100) diffraction ring, and (c) electron diffraction pattern acquired from the same area of (a) and (b).

cubic indexes to help interpret changes in the diffraction patterns with lithiation.

Bright-field and dark-field TEM was performed on the ball-milled carbon- $\mathrm{FeF}_{3}$ nanocomposite. Images acquired from the same region of the sample are shown in Fig. 2. The bright-field image in Fig. 2(a) shows the aggregated $\mathrm{FeF}_{3}$ nanoparticles surrounded by amorphous carbon. The dark-field image in Fig. 2(b) was taken using the $\mathrm{FeF}_{3}$ (100) diffraction ring $(\mathrm{d}=3.60 \AA)$. An average particle size of $15 \pm$ $8 \mathrm{~nm}$ was determined from examining several regions of the sample, which is consistent with the value of $18 \mathrm{~nm}$ obtained from XRD. In the electron diffraction pattern of the carbon- $\mathrm{FeF}_{3}$ nanocomposite shown in Fig. 2(c), the innermost fine ring corresponds to the $10 \mu \mathrm{m}$ $\mathrm{SAD}$ aperture used to obtain the diffraction pattern. The remaining diffraction rings visible in Fig. 2(c) match well with indexes of $\mathrm{FeF}_{3}$ as 

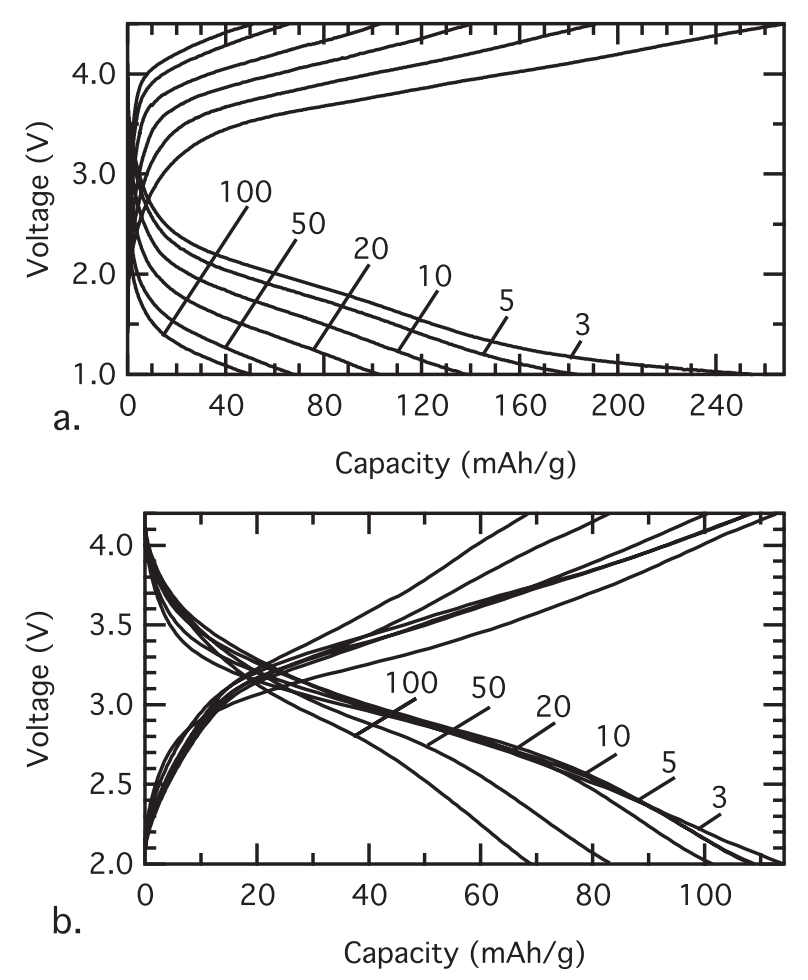

Figure 3. Cycling curves for coin cells cycled at $\pm 142 \mathrm{~mA} / \mathrm{g}$ between (a) $4.5 \mathrm{~V}$ and $1.0 \mathrm{~V}$ and (b) $4.5 \mathrm{~V}$ and $2.0 \mathrm{~V}$. Each cell underwent 100 cycles. The 3rd, 5th, 10th, 20th, 50th, and 100th cycles are shown.

a $\mathrm{ReO}_{3}$ cubic structure, consistent with the XRD pattern of Fig. 1(b). A number of electron diffraction patterns were taken and impurities from ball-milling such as Fe or Mn metals were not found, neither were any additional elements visible by energy-dispersive X-ray spectroscopy (EDS) analysis of the milled materials.

Electrochemical measurements. - Electrochemical cycling tests were performed using a constant current of $\pm 142 \mathrm{~mA} / \mathrm{g}$. This rate is equivalent to $\mathrm{C} / 5$ for a three-electron conversion from $\mathrm{FeF}_{3}$ to $\mathrm{Fe}$ with a theoretical capacity of $710 \mathrm{mAh} / \mathrm{g}$. One set of tests was performed over 10 cycles with a maximum voltage of $4.5 \mathrm{~V}$ and minimum discharge voltages of 1.0, 1.25, 1.5, 1.75, and $2.0 \mathrm{~V}$. Differences in performance were most prominent between discharge voltages of 1.0 and $2.0 \mathrm{~V}$. A second set of tests investigated discharge voltages of 1.0 and $2.0 \mathrm{~V}$ over a larger number of cycles. Figure 3 shows voltage versus capacity curves for selected cycles over 100-cycle tests between 1.0 to $4.5 \mathrm{~V}$, and 2.0 to $4.5 \mathrm{~V}$. The cells undergoing the "deep discharge" to $1.0 \mathrm{~V}$ showed a large voltage hysteresis between charge and discharge, ranging from $2.2 \mathrm{~V}$ to $3.1 \mathrm{~V}$ measured when the cell is at $50 \%$ SOC upon charge or discharge. Moreover, comparing capacity values from charge and discharge in the same cycle, a very low energy efficiency was observed, mainly resulting from the large voltage hysteresis. These discharge profiles had large slopes, and the discharge capacity faded quickly during cycling. The cells undergoing the "shallow discharge" to $2.0 \mathrm{~V}$ showed a voltage plateau between 3.0 and $2.7 \mathrm{~V}$ that underwent little change up to 20 cycles. Their capacity decreased slowly upon cycling, with the slope of the discharge curve increasing gradually. The voltage hysteresis remained around $0.7 \mathrm{~V}$ to the 100th cycle. The voltage hysteresis during cycling with a "shallow discharge" was much smaller than for the "deep discharge", consistent with previous cyclic voltammetry results ${ }^{16}$ which are discussed in the next section.

The performance of the cathode material may be better demonstrated by comparing the relative capacities versus cycle number for the different depths of discharge. In Fig. 4(a), the charge and discharge capacities relative to the charge capacity in the third cycle are plotted
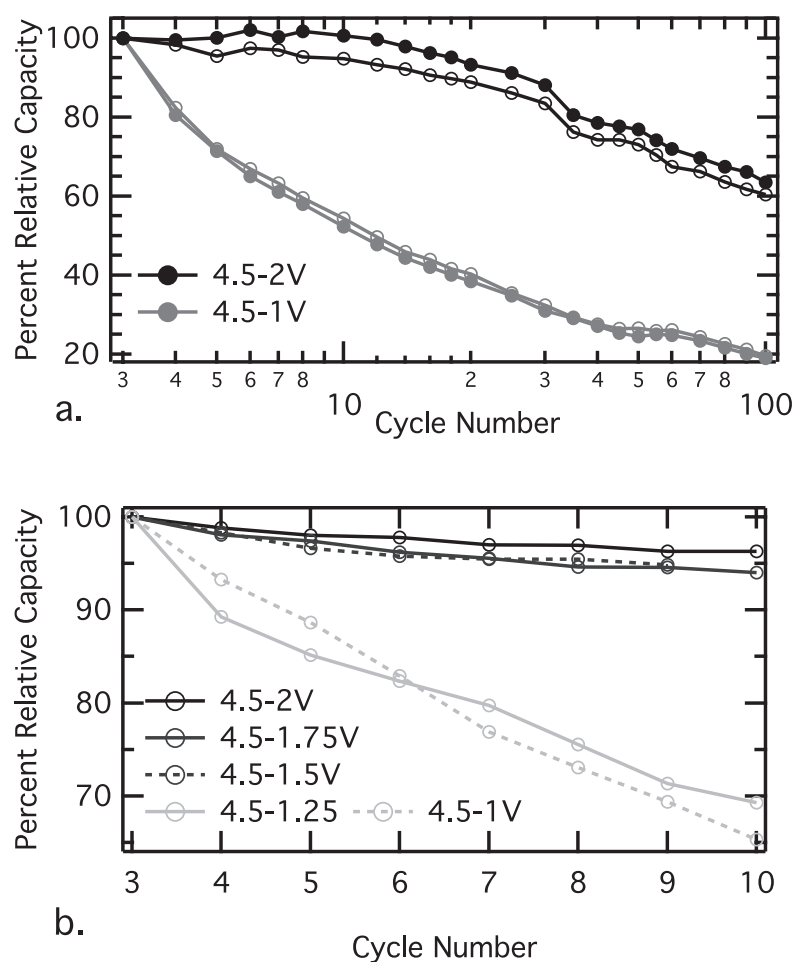

Figure 4. Comparison of charge capacities (solid circles) and discharge capacities (empty circles) relative to the third charge versus cycle number. (a) Relative capacities from tests of 100 cycles with a C/5 rate shown in Fig. 3. (b) Relative capacities from tests of the first 10 cycles, showing capacities during discharge only.

versus cycle number. Shown in Fig. 4(b), even over 10 cycles, there are obvious differences in the capacity fade as a function of minimum discharge voltage. When discharged to $2.0 \mathrm{~V}$, the capacity loss after 10 cycles was $4 \%$, whereas discharging to $1.75 \mathrm{~V}$ and $1.5 \mathrm{~V}$ caused capacity losses of $5 \%$ and $6 \%$, respectively. For deeper discharges below $1.5 \mathrm{~V}$, the capacity losses in 10 cycles jumped to greater than $30 \%$. These differences were even more prominent after further cycles (Fig. 4(b)). For shallow cycling between 4.5 and $2.0 \mathrm{~V}$, both charge and discharge capacities were stable for the first ten cycles, decreased approximately $10 \%$ between cycles 10 and 20, and reached $100 \mathrm{cy}-$ cles with over $60 \%$ capacity remaining. Deep cycling between 4.5 and $1.0 \mathrm{~V}$ gave a fade in capacity to $50 \%$ after 10 cycles, an additional fade to $40 \%$ between cycles 10 and 20 , and less than $20 \%$ capacity remained after 100 cycles.

In situ XRD. - A set of in situ XRD measurements were performed on uncycled pouch cells at a C/100 discharge rate to study the Stage 1 of lithiation. A typical voltage profile during this in situ measurement is shown in Fig. 5, where XRD patterns of the cathode composite were acquired at several different steps during discharge, marked as A to F. The corresponding XRD patterns are shown in Fig. 6, also labeled as $\mathrm{A}$ to $\mathrm{F}$. Indexed to the cubic $\mathrm{ReO}_{3}$ structure, the first five peaks - (100), (110), (111), (200), (210) are seen clearly before the discharge starts (pattern A in Fig. 5). As lithium ions enter the $\mathrm{FeF}_{3}$ cell, the intensities of the (100) and (110) peaks decrease sharply, to less than $10 \%$ in step $\mathrm{C}$. The (111) peak has a slight shift to higher diffraction angle from steps $\mathrm{A}$ to $\mathrm{C}$ of about $0.3^{\circ}$ in $2 \theta$ angle, followed by a larger shift to lower diffraction angle from steps $\mathrm{C}$ to $\mathrm{F}$ of about $1^{\circ}$. The (210) peak has a large shift of about $2^{\circ}$ to lower diffraction angle from steps A to F, but the position of the (200) peak remains nearly unchanged.

A unit cell of rhombohedral $\mathrm{FeF}_{3}$ was modeled using CrystalMaker ${ }^{\circledR}$, with the lattice parameters $a=3.734 \AA$, and $\alpha=88.23^{\circ}$. This structure is very close to that of cubic $\mathrm{ReO}_{3}$ shown 


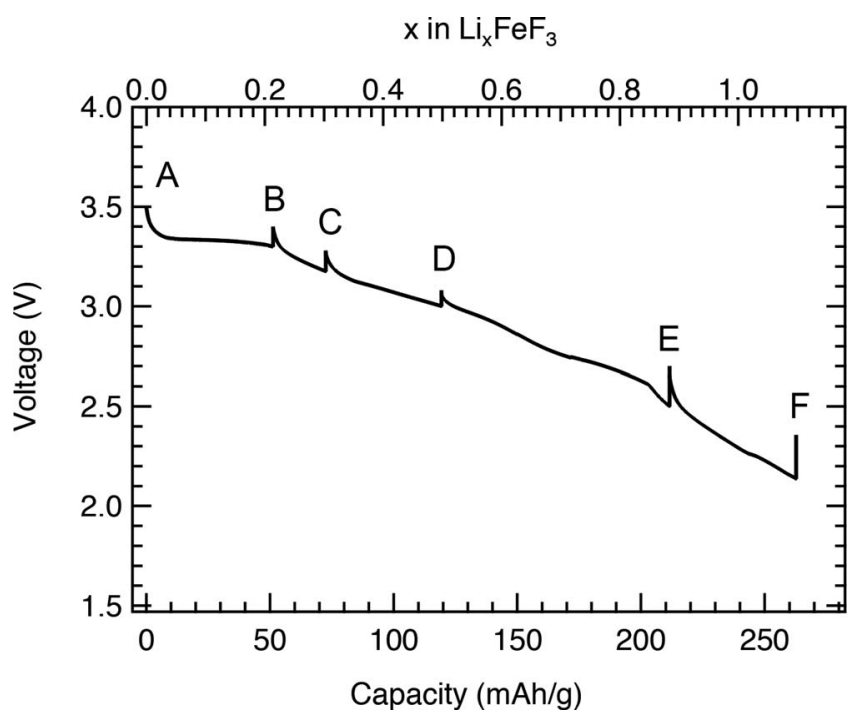

Figure 5. A typical galvanostatic discharge profile during the in situ XRD measurement, showing where the points where XRD patterns were acquired $\mathrm{A}$ before the discharge, and at the nominal lithium concentrations, $\mathrm{B} \mathrm{Li}_{0.2} \mathrm{FeF}_{3}$, $\mathrm{CLi}_{0.3} \mathrm{FeF}_{3}, \mathrm{D} \mathrm{Li}_{0.5} \mathrm{FeF}_{3}, \mathrm{E} \mathrm{Li}_{0.85} \mathrm{FeF}_{3}, \mathrm{~F} \mathrm{Li}_{1.1} \mathrm{FeF}_{3}$. in Fig. 6(c) with $\alpha=90^{\circ}$. The atom positions are also consistent with the alternative rhombohedral unit cell used previously ( $a=5.362 \AA$, $\left.\alpha=58^{\circ}\right),{ }^{5,6}$ except for the missing (111) diffraction caused by the cancelation of $\mathrm{Fe}$ and $\mathrm{F}$ atomic form factors in a perfect cubic lattice. Different locations for lithium sites in the structure were tested, and diffraction patterns simulated. The measured changes of the in situ diffraction patterns with lithiation, especially the reduction in intensity of the (100) diffraction and the large shift of the (210), were reproduced reasonably well when the $\mathrm{Li}^{+}$ion was inserted along the body diagonal of the cubic $\mathrm{FeF}_{3}$ unit cell near three $\mathrm{F}^{-}$ions, with the cell undergoing a small decrease of rhombohedral angle $\alpha$ of approximately $1^{\circ}$. The distortion of the unit cell with $\mathrm{Li}^{+}$insertion is primarily an elongation of the cubic cell along the body diagonal line in which the original (100) interplanar spacing increases by only $0.5 \%$. The volume of the unit cell increases with the $\mathrm{Li}^{+}$insertion, as may be expected.

\section{Discussion}

Based on the capacity values obtained above, and consistent with the proposal of a topotactic lithiation mechanism, ${ }^{5}$ Stage 1 lithiation occurs when $\mathrm{FeF}_{3} / \mathrm{Li}$ is discharged to approximately $2 \mathrm{~V}: 6,11,16$

$$
\mathrm{FeF}_{3}+x \mathrm{Li} \rightarrow \mathrm{Li}_{x} \mathrm{FeF}_{3}, \quad 0<x<1 \quad \text { (Stage 1), }
$$

which we studied as "shallow discharge". Most previous studies on $\mathrm{FeF}_{3}$ used "deep discharge" that included both Stage 1 and Stage 2
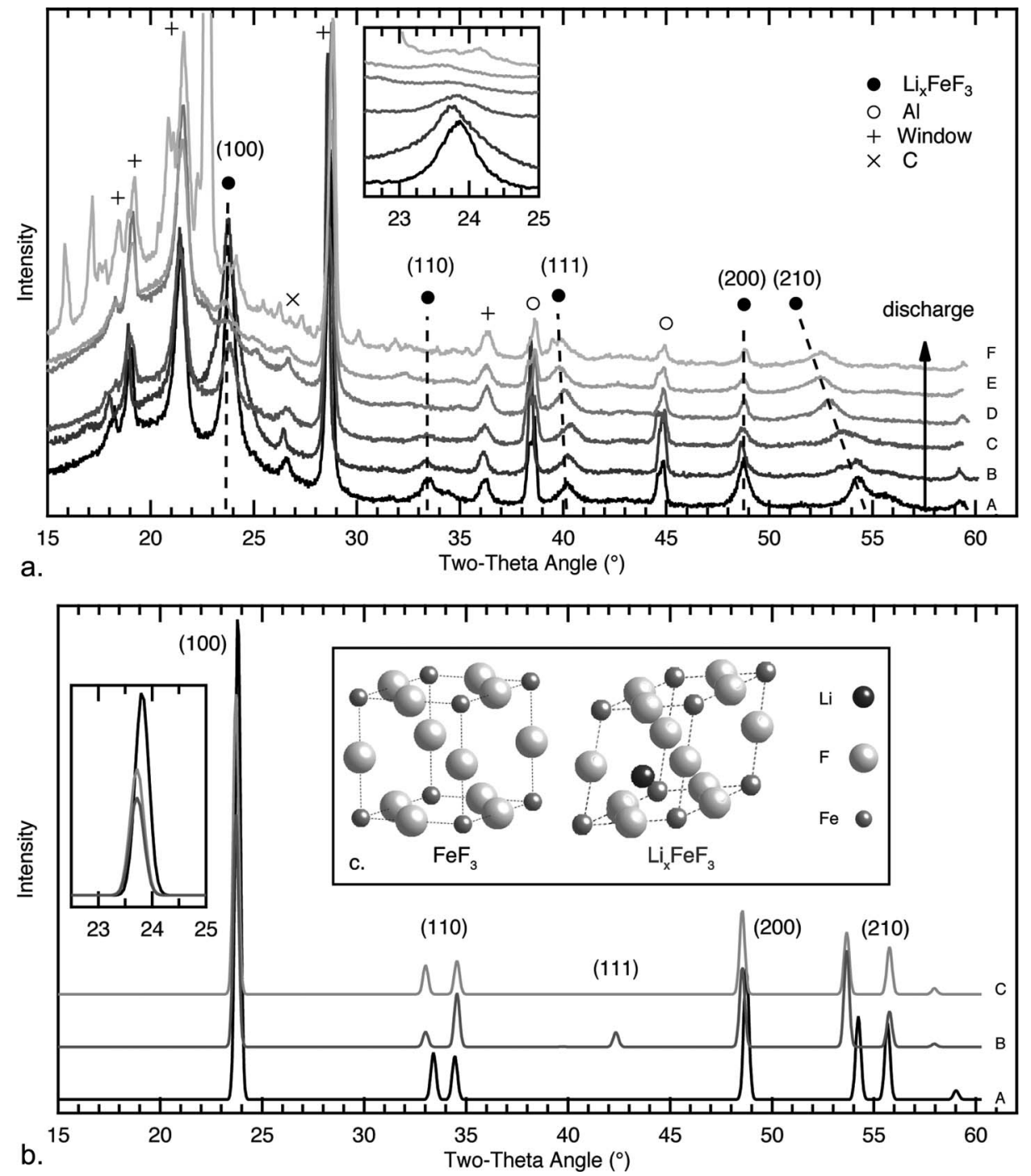

Figure 6. (a) XRD patterns from the in situ discharge measurements. Labels A-F on the right correspond to the stages of lithiation indicated in Fig. 5, where the black curve A was obtained before discharge. (b) Simulated XRD patterns from $\mathrm{FeF}_{3}$ (curve $\mathrm{A}$, black) and $\mathrm{Li}_{x} \mathrm{FeF}_{3}$ (curve $\mathrm{B}$, gray), using the unit cells depicted in the inset (c). Curve C (light gray) is simulated from the lithiated structure with rhombohedral distortion and additional $30 \% \mathrm{Li}$-Fe site substitution. 
when the cell voltage was reduced to $1 \mathrm{~V}$ versus Li. For deep discharge the overall reaction is

$$
\mathrm{FeF}_{3}+3 \mathrm{Li} \rightarrow \mathrm{Fe}+3 \mathrm{LiF} \quad(\text { Stage } 1+2) .
$$

With deep discharge, galvanostatic cycling gives a high capacity, but shows two issues: a large voltage hysteresis and poor cycle life. The hysteresis was systematically studied using cyclic voltammetry and galvanostatic cycling under quasi-static conditions by Liu et al. ${ }^{16}$ In this work, the cyclic voltammograms with a $2 \mathrm{~V}$ lower potential cutoff showed only about $0.25 \mathrm{~V}$ difference between the two redox peaks. Whereas in the case of $1 \mathrm{~V}$ lower potential cutoff, the second redox reaction corresponding to the Stage 2 exhibits around $1 \mathrm{~V}$ difference between the oxidizing and reducing peaks. Therefore, a large difference of energy efficiency is expected between the "shallow discharge" and "deep discharge". It was also reported that the large activation energy of forming $\mathrm{Fe} / \mathrm{LiF}$ composite phases during discharge was the intrinsic cause of the large voltage hysteresis. ${ }^{16}$ The capacity fade during cycling to deep discharge is less well understood, although prior studies have shown the formation of a number of different phases including LiF, which may be electrochemically inactive. In the course of this work we also performed in situ XRD on materials subjected to deep discharges through Stage 2, but the diffraction patterns were complicated and inconsistent.

The large difference in cycle life between deep and shallow discharging shown in Fig. 4 suggests distinctly dissimilar lithiation mechanisms for Stages 1 and 2, and this is consistent with the evidence for topotactic insertion ${ }^{5}$ of lithium in Stage 1 and the formation of new phases in Stage 2. Figures 3 and 4 show that the problems of capacity fade and hysteresis are greatly ameliorated when the cycling is limited to Stage 1. Although most previous studies focused on the higher capacity performance obtained with Stage 2, a better understanding of the lithiation mechanism in Stage 1 helps to explain the differences in cycle life shown in Fig. 4.

Stage 1 corresponds to the insertion of up to one $\mathrm{Li}^{+}$ion per $\mathrm{FeF}_{3}$ unit cell. Figure 6(c) depicts a plausible configuration where the $\mathrm{Li}^{+}$ ion is situated to allow a symmetrical rhombohedral shear, and is approximately consistent with the shifts of the measured diffraction peaks. If $\mathrm{a} \mathrm{Li}^{+}$ion is inserted along the body diagonal line in the $\mathrm{FeF}_{3}$ unit cell, it may attract three neighboring $\mathrm{F}^{-}$ions on the edge, promoting the shear of the unit cell. There is some degree of ambiguity in this modeling because the $\mathrm{FeF}_{3}$ crystallites are both small and probably have some lattice strain. There is a tendency for the higher-order diffraction peaks to be broader than the lower-order ones, a characteristic of strain distribution in the material, but this is not practical to quantify with the present XRD patterns. The nanocrystals of $\mathrm{FeF}_{3}$ are consolidated into larger particles, and another strain effect arises when individual crystals or parts of them begin to undergo rhomobohedral shears. The elastic constraint from surrounding regions does not allow the full transformation strain that occurs without constraint, for which we expect a larger change in $\alpha$-angle. A distribution of $\alpha$-angles may be responsible for the large broadening of the (210) diffraction peak, in particular.

A second feature of the diffraction patterns is the large decrease in intensity of the (100) diffraction peak with lithiation. This is also consistent with a previous observation by $e x$-situ XRD. ${ }^{12}$ Some such change is calculated with the $\mathrm{Li}^{+}$insertion and rhomobohedral shear, but the measured changes in intensity are much larger. Such a large change can only occur if $\mathrm{Fe}$ atoms, which scatter X-rays strongly, occupy sites near the center of the cubic unit cell. These anti-site Fe atoms scatter X-rays out of phase to suppress the (100) diffractions. As an example with the structure of Fig. 6(c), a 30\% interchange of Li and $\mathrm{Fe}$ atoms accounts accurately for the intensity changes as is seen the simulated pattern in Fig. 6(b). Other point defects can explain the changes in the diffraction pattern, but some Fe disorder is required. In spite of these ambiguities, it is evident from our in situ measurements that lithiation involves a continuous topotactic insertion of $\mathrm{Li}$ through the discharge of Stage 1. In Stage 1 we did not find evidence for the formation of rutile $\mathrm{FeF}_{2}$ or $\mathrm{LiF}^{11,14,17}$ but for coin cells discharged to below $1.5 \mathrm{~V}$ the diffraction peaks from $\mathrm{LiF}$ were prominent, along with unidentified reaction products.

We found that by limiting the discharge voltage within Stage 1, the cycle life of nanostructured $\mathrm{FeF}_{3}$ improves dramatically. Nevertheless, there is still some loss of capacity over time. The capacity fade may be rate dependent. During slow discharge, the voltage and capacity were much larger than shown in Fig. 3. Note in Fig. 5, for example, that the discharge capacity at $2 \mathrm{~V}$ was approximately $250 \mathrm{mAh} / \mathrm{g}$, whereas it was $115 \mathrm{mAh} / \mathrm{g}$ during the faster cycling of Fig. 3(b).

There are other challenges when using $\mathrm{FeF}_{3}$ as a cathode. For example, the cell must be prepared with a pre-lithiated anode. Although almost all previous studies of $\mathrm{FeF}_{3}$ used lithium metal as the anode, the dendrite issue of lithium metal likely prevents its use in practical applications. Other pre-lithiated anodes may warrant further investigation. Another approach is preparing the cathode in a lithiated form such as $\mathrm{LiFeF}_{3}$ or $\mathrm{Li}_{0.5} \mathrm{FeF}_{3}$. This approach has shown promise, ${ }^{14,15,18}$ but more work is needed to synthesize materials with the correct stoichiometry and crystal structure.

\section{Summary}

Nanocrystalline $\mathrm{FeF}_{3}$ was prepared and studied as a cathode material for rechargeable lithium batteries. For the first time, the cycle life was measured with different cutoffs for the discharge voltage. It was found that by limiting the discharge within Stage 1, i.e., storing less than one lithium per $\mathrm{FeF}_{3}$, both the cycle life and energy efficiency are dramatically improved compared to converting $\mathrm{FeF}_{3}$ into $\mathrm{Fe}$ and LiF by deep discharge. An in situ XRD study of the initial discharge in Stage 1 showed a continuous change of the peak intensity and position from the original $\mathrm{FeF}_{3}$ diffraction pattern. A lithium intercalation mechanism was proposed in which the partial $\mathrm{Li}$ occupancy inside the rhombohedral $\mathrm{FeF}_{3}$ unit cell slightly distorts its lattice parameters without nucleating a new crystal structure. This mechanism is consistent with the observed highly reversible $\mathrm{FeF}_{3}$ cathode performance.

\section{Acknowledgment}

The authors thank Dr. Ratnakumar Bugga at NASA Jet Propulsion Lab, Dr. Ilias Belharouak at Argonne National Lab, Dr. Meng Jiang at General Motors for insightful discussions, and Dr. Cedric Weiss at Contour for experimental assistance with the in situ apparatus. This work was supported as part of EFree, an Energy Frontier Research Center, under Award No. DE-SG0001057.

\section{References}

1. J.-M. Tarascon and M. Armand, Nature, 414, 359 (2001).

2. X. Yuan, H. Liu, and J. Zhang, (CRC Press, Boca Raton, FL, 2012)

3. J. Cabana, L. Monconduit, D. Larcher, and M. R. Palacin, Adv. Mater., 22, E170 (2010).

4. H. Arai, S. Okada, Y. Sakurai, and J. Yamaki, J. Power Sources, 68, 716 (1997)

5. F. Badway, N. Pereira, F. Cosandey, and G. G. Amatucci, J. Electrochem. Soc., 150, A1209 (2003)

6. F. Badway, F. Cosandey, N. Pereira, and G. G. Amatucci, J. Electrochem. Soc., 150, A1318 (2003)

7. H. Li, G. Richter, and J. Maier, Adv. Mater., 15, 736 (2003).

8. M. Nishijima, I. D. Gocheva, S. Okada, T. Doi, J. Yamaki, and T. Nishida, J. Power Sources, 190, 558 (2009)

9. T. Li, L. Li, Y. L. Cao, X. P. Ai, and H. X. Yang, J. Phys. Chem. C, 114, 3190 (2010).

10. L. Li, F. Meng, and S. Jin, Nano Lett., 12, 6030 (2012).

11. N. Yamakawa, M. Jiang, B. Key, and C. P. Grey, Chem. Mater, 21, 3162 (2009).

12. M. Zhou, L. Zhao, A. Kitjou, S. Okada, and J. Yamaki, J. Power Sources, 203, 103 (2012).

13. R. Prakash, A. K. Mishra, A. Roth, C. Kubel, T. Scherer, M. Ghafari, H. Hahn, and M. Fichtner, J. Mater. Chem., 20, 1871 (2010).

14. G. G. Amatucci, N. Pereira, F. Badway, M. Sina, F. Cosandey, M. Ruotolo, and C. Cao, J. FLuorine Chem., 132, 1086 (2011).

15. P. Liao, R. A. Dunlap, and J. R. Dahn, J. Electrochem. Soc., 157, A1080 (2010).

16. P. Liu, J. J. Vajo, J. S. Wan, W. Li, and J. Liu, J. Phys. Chem. C, 116, 6467 (2012).

17. R. E. Doe, K. A. Perssan, Y. S. Meng, and G. Ceder, Chem. Mater, 20, 5274 (2008).

18. P. Liao, J. Li, and J. R. Dahn, J. Electrochem. Soc., 157, A355 (2010). 